\title{
HUBUNGAN ANTARA DUKUNGAN KELUARGA DAN KEPATUHAN MINUM OBAT DENGAN KEKAMBUHAN KLIEN GANGGUAN JIWA BERAT
}

\author{
Alber Tanjung, Novy CD Helena ${ }^{2}$, Dewi Eka Putri ${ }^{3}$ \\ Mahasiswa Program Studi Magister Keperawatan Universitas Andalas Padang \\ Email: albertanjung6@gmail.com \\ Dosen Ilmu Keperawatan Universitas Indonesia Depok \\ Email: novi_hc@ui.ac.id \\ Dosen Fakultas Keperawatan Universitas Andalas Padang \\ Email: dewiekaputri@nrs.unand.ac.id
}

\begin{abstract}
ABSTRAC
National prevalence of severe mental disorder is 1,7 per mil meaning 1-2 person in 1000 resident suffered from severe mental disorder. The highest prevalence is in Daerah Istimewa Yogyakarta and Aceh (0,27\%). Prevalence of severe mental disorder in West Sumatera is $(0,19 \%)$. This study was aimed to get an overview of relationship between family support and medication compliance with clients recurrence in severe mental disorder. Analytical design with cross sectional with the number of respondents 184 clients of severe mental disorder and family in Mental Care Unit A RSJ. Prof. Dr. HB. Saanin Padang. Samples in this study were taken with purposive sampling technique. Data were collected through questionnaires of family support and medication compliance. Research shows that there are significant difference between family support with high recurrence and low recurrence $(p<0.05)$, no significant difference between medication compliance with high recurrence and low recurrence $(p<0.05)$, Results of this study are expected to be contribution for nurses and related institutions in order to advise the family to oversee the client to take medication on a regular basis so that recurrence can be prevented, providing related penkes on taking medication and home settings visite.
\end{abstract}

Keywords: family support, medication compliance, reccurence clients of severe mental disorder

\begin{abstract}
ABSTRAK
Prevalensi gangguan jiwa berat secara Nasional 1,7 per mil yang berarti 1-2 orang dalam 1000 penduduk mengalami gangguan jiwa berat. Prevalensi gangguan jiwa berat tertinggi di Daerah Istimewa Jogjakarta dan Aceh (0.27\%), sedangkan prevalensi gangguan jiwa berat di Sumatera Barat mencapai (0.19\%) . Penelitian ini bertujuan untuk mendapatkan gambaran tentang hubungan antara dukungan keluarga dan kepatuhan minum obat dengan kekambuhan pada klien gangguan jiwa berat. Desain Analitik dengan pendekatan potong lintang (Cross sectional) dengan jumlah responden 184 orang klien gangguan jiwa berat dan keluarga di Unit Pelayanan Jiwa A RSJ. Prof. Dr. HB. Saanin Padang. Pengambilan sampel dalam penelitian ini dengan teknik purposive sampling. Pengumpulan data dilakukan menggunakan kuesioner dukungan keluarga dan kepatuhan minum obat. Hasil Penelitian menunjukkan bahwa ada perbedaan yang signifikan antara dukungan keluarga dengan kekambuhan tinggi dan kekambuhan rendah dengan nilai $(p<0,05)$, ada perbedaan yang signifikan antara kepatuhan minum obat dengan kekambuhan tinggi dan kekambuhan rendah dengan nilai $(p<0,05)$. Hasil penelitian ini diharapkan menjadi masukkkan bagi perawat dan intansi terkait agar menganjurkan kepada keluarga untuk mengawasi klien untuk minum obat secara teratur agar kekambuhan dapat di cegah,memberikan penkes terkait pengaturan minum obat dan home visite.
\end{abstract}

Kata kunci : dukungan keluarga, kepatuhan minum obat, kekambuhan klien gangguan jiwa berat. 


\section{PENDAHULUAN}

Kesehatan merupakan keadaan sejahtera dari badan, jiwa dan sosial yang memungkinkan seseorang hidup produktif baik secara sosial maupun ekonomi Kesehatan jiwa masih menjadi salah satu permasalahan kesehatan yang signifikan di dunia, termasuk di Indonesia. Menurut World Health Organization (2017) Kesehatan dapat menjadi investasi dalam meningkatkan kualitas sumber daya manusia sehingga kesehatan harus dilihat secara keseluruhan dimana kesehatan jiwa menjadi salah satu bagian yang sangat penting dalam hal tersebut. Kesehatan jiwa bisa di artikan sebagai suatu kondisi sehat baik emosional, psikologis, dan juga sosial yang ditunjukkan dalam hubungan interpersonal yang memuaskan antara individu dengan individu yang lain, memiliki koping ysng efektif, kondep diri positif dan emosi yang stabil (Videbeck, 2010). Tidak berkembangnya koping individu secara baik dapat menyebabkan terjadinya gangguan jiwa.

Gangguan jiwa tersebar hampir merata di seluruh dunia, termasuk di wilayah Asia Tenggara. Berdasarkan data dari World Health Organization (WHO), hampir satu per tiga dari penduduk di wilayah Asia Tenggara pernah mengalami gangguan jiwa. Berkaitan dengan angka gangguan jiwa di Indonesia sendiri, menurut WHO (2017), prevalensi

\section{HASIL DAN PEMBAHASAN}

Tabel 5.1

Distribusi Karakteristik Umur Klien Gangguan Jiwa Berat di Unit Pelayanan Jiwa A RSJ. Prof. Dr. HB, Saanin Padang ( $=184)$

\begin{tabular}{ccccc}
\hline $\begin{array}{c}\text { Karakteristi } \\
\mathbf{k}\end{array}$ & Mean & SD & $\begin{array}{c}\text { Min- } \\
\text { maks }\end{array}$ & $\mathbf{9 5 \% ~ C l ~}$ \\
\hline Umur & 40.33 & 10.947 & $19-65$ & $38.74-41.92$ \\
\hline
\end{tabular}

gangguan jiwa yang ada di Indonesia mencapai $13 \%$ dan masih memungkinkan untuk berkembang lagi menjadi $25 \%$ di tahun 2030. Menurut Dinas Kesehatan Kota dari jumlah penduduk di Kota Padang yang mengalami gangguan jiwa sebanyak $0,75 \%$ sedangkan pada tahun sebelumnya yaitu tahun 2008 ada sekitar $0,26 \%$ yang menderita gangguan jiwa. Terjadi Peningkatan 0,49\% dalam kurun waktu setahun, artinya kondisi ini berarti ada sebanyak $\geq 200$ ribu penduduk kota Padang yang mengalami gangguan jiwa.

METODE PENELITIAN

Penelitian ini mempergunakan desain Analitik dengan pendekatan potong lintang (Cross sectional), dimana peneliti akan mempelajari hubungan antar variabel independen dengan melakukan pengukuran sesaat. Faktor risko serta efek tersebut di ukur menurut keadaan atau statusnya pada waktu penelitian dengan mengunakan kuesioner, jadi tidak ada tindak lanjut atau follow up.

Penelitian ini dilaksanakan di Unit Pelayanan Jiwa A Rumah Sakit Jiwa Prof. HB. Saanin Padang tahun 2015. Populasi klien gangguan jiwa berat di Unit Pelayanan Jiwa A Rumah Sakit Jiwa Prof. HB. Saanin Padang selama 3 bulan terakhir (Maret, April, Mei 2015) yang berjumlah 3099orang. Cara pengambilan sampel dalam penelitian ini dengan teknik purposive sampling.

\footnotetext{
Berdasarkan tabel 5.1 diketahui rata-rata umur 40.33, $(95 \% \quad \mathrm{Cl}$ 38.74-

41.92) umur termuda 19 tahun dan umur tertua

65 tahun.
} 
Tabel 5.2

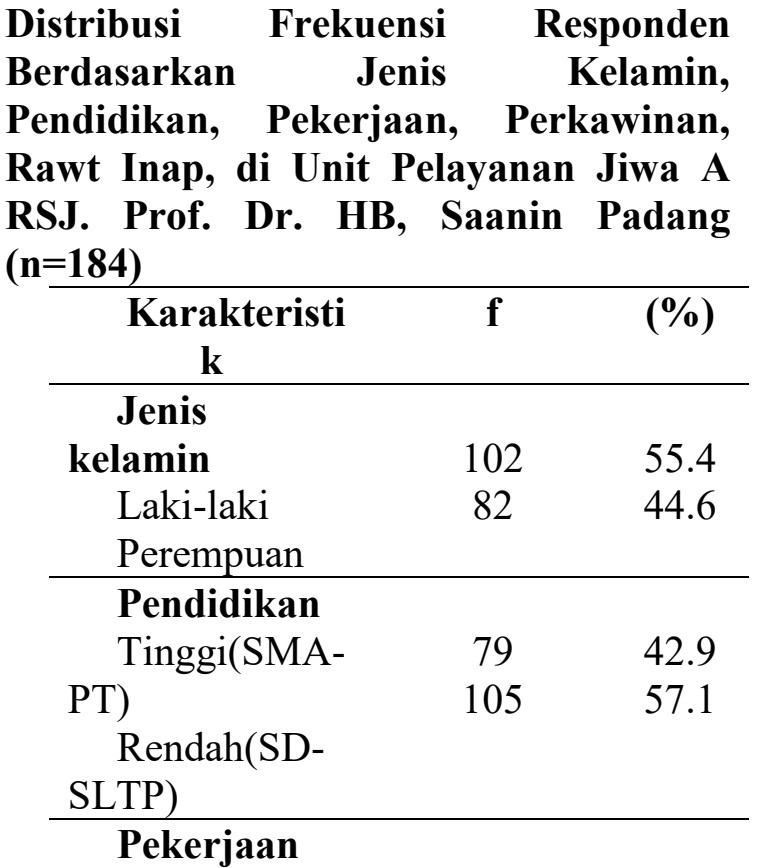

\begin{tabular}{lcc}
\hline Kerja & 17 & 9.2 \\
Tidak bekerja & 167 & 90.8 \\
\hline Perkawinan & & \\
Menikah & 38 & 20.7 \\
Belum & 123 & 66.8 \\
menikah & 23 & 12.5 \\
$\quad$ Janda/Duda & & \\
\hline Rawat Inap & & \\
Pernah & 105 & 57.1 \\
Tidak Pernah & 79 & 42.9 \\
\hline
\end{tabular}

Berdasarkan tabel 5.2, hasil analisis didapatkan lebih dari separuh klien berjenis kelamin laki-laki (55.4\%), hampir separuh klien berpendidikian rendah (57.1\%), lebih dari separuh klien tidak bekerja (90.8\%), lebih dari separuh klien belum menikah (66.8\%), lebih dari separuh klien pernah di rawat inap (57.1\%)

Tabel 5.3

Distribusi Frekuensi Responden Berdasrkan Kekambuhan Unit Pelayanan Jiwa A RSJ. Prof. Dr. HB, Saanin Padang (n=184)

\begin{tabular}{ccccc}
\hline Kekambuhan & F & $\%$ & \\
\hline Tinggi & 110 & 59,8 & \\
\hline Rendah & 72 & 40,2 & \\
\hline Total & 184 & 100 & \\
Berdasarkan tebel 5.3dapat terbaca & $(59.8 \%)$ & responden & mengalami
\end{tabular}

lebih bahwa dari separuh responden kekambuhan tinggi

Tabel 5.4

Distribusi Frekuensi Responden Berdasarkan Dukungan Keluarga Klien Gangguan Jiwa Berat di Unit Pelayanan Jiwa A RSJ. Prof. Dr. HB, Saanin Padang $(n=184)$

\begin{tabular}{cccccc}
\hline Variabel & $\begin{array}{c}\text { Med } \\
\text { ian }\end{array}$ & $\begin{array}{c}\mathrm{M} \\
\text { ean }\end{array}$ & \multicolumn{1}{c}{ SD } & Min-maks & $95 \%$ CI \\
\hline Dukungan & 50.0 & 49 & 5.47 & $38-63$ & $49.04-50.63$ \\
Keluarga & 0 & .83 & 4 & & \\
\hline
\end{tabular}

Berdasarkan Tabel 5.4 didapatkan hasil anlisis diketahui rata-rata dukungan keluarga responden secara keseluruhan adalah 49.83. Skor dukungan keluarga terendah 38 dan dukungan tertinggi 63 . Tabel 5.5

Distribusi Frekuensi Kepatuhan Minum Obat Klien Gangguan Jiwa Berat di Unit Pelayanan Jiwa A RSJ. Prof.HB. Saanin Padang( $(\mathbf{n}=184)$

Variabel
Hasil estimasi interval dapat disimpulkan bahwa 95\% diyakini rata-rata dukungan keluarga responden adalah diantara 49.04sampai dengan 50.63.

\begin{tabular}{rlll}
\hline & $\mathrm{n}$ & $\mathrm{n}$ & \\
\hline Kepatuhan & 9.00 & 8.67 & $\begin{array}{l}1.08 \\
\text { Minum Obat }\end{array}$ \\
\end{tabular}

Berdasarkan Tabel 5.5 didapatkan hasil

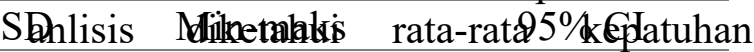


minum obat responden secara keseluruhan adalah 8.67. Skor kepatuhan minum obat terendah 6 dan kepatuhan tertinggi 10 . Hasil estimasi interval dapat disimpulkan bahwa 95\% diyakini rata-rata kepatuhan minum obat responden adalah diantara 8.51 sampai dengan 8.83 .

Tabel 5.6

Hubungan Antara Dukungan Keluarga Dengan Kekambuhan Klien Gangguan Jiwa Berat di Unit Pelayanan Jiwa A RSJ. Prof. Dr. HB, Saanin Padang (n=184)

\begin{tabular}{lcrrccc}
\hline & $\begin{array}{c}\text { Kekambu } \\
\text { han }\end{array}$ & $\mathbf{n}$ & $\begin{array}{c}\text { M } \\
\text { ean }\end{array}$ & $\begin{array}{c}\text { Std. } \\
\text { Deviation }\end{array}$ & $\begin{array}{c}\text { Std. } \\
\text { Error } \\
\text { Mean }\end{array}$ & P Value \\
\hline Dukun & Tinggi & 1 & 45. & 3.702 & .430 & 0,000 \\
gan & & 10 & 55 & & & \\
& Rendah & 7 & 52. & 4.512 & .430 & \\
& & 4 & 71 & & & \\
\hline
\end{tabular}

Berdasarkan tabel 5.6 Rata-rata kekambuhan klien gangguan jiwa berat rendah adalah 52.71 dengan standar deviasi 4,152, sedangkan untuk kekambuhan tinggi, rata-rata kekambuhannya adalah 45.55 dengan

Tabel 5.7

Hubungan Antara Kepatuhan Minum Obat Dengan Kekambuhan Klien Gangguan Jiwa Berat di Unit Pelayanan Jiwa A RSJ. Prof. Dr. HB, Saanin Padang (n=184)

\begin{tabular}{ccrrccc}
\hline & $\begin{array}{c}\text { Kekambu } \\
\text { han }\end{array}$ & $\mathbf{n}$ & $\begin{array}{c}\text { M } \\
\text { ean }\end{array}$ & $\begin{array}{c}\text { Std. } \\
\text { Deviation }\end{array}$ & $\begin{array}{c}\text { St } \\
\text { d. } \\
\text { Error } \\
\text { Mean }\end{array}$ & $\begin{array}{c}\boldsymbol{P} \\
\text { Value }\end{array}$ \\
\hline Kepatu & Tinggi & 1 & 7.8 & 1.034 & .12 & 0.000 \\
han & 10 & 4 & & 0 & \\
& Rendah & 7 & 9.2 & .686 & .06 & \\
& & 4 & 3 & .686 & \\
\hline
\end{tabular}

Berdasarkan tabel 5.7 Rata-rata kekambuhan klien gangguan jiwa berat rendah adalah 9.2 dengan standar deviasi 686, sedangkan untuk kekambuhan tinggi , rata-rata kekambuhannya adalah 7.84 dengan standar deviasi 1.03. Hasil statistik didapatkan nilai $p=0.000$ ada perbedaan yang signifikan antara kepatuhan minum obat dengan kekambuhan tinggi dan kekambuhan rendah. standar deviasi 3.702. Secara statistik didapatkan nilai $p=0.000$ ada perbedaan yang signifikan antara dukungan keluarga dengan kekambuhan tinggi dan kekambuhan rendah. 
Hubungan Antara Dukungan Keluarga Dengan Kekambuhan Klien Gangguan Jiwa Berat di Unit Pelayanan Jiwa A RSJ. Prof. Dr. HB, Saanin Padang.

Berdasarkan hasil penelitian didapat rata-rata dukungan keluarga dengan kekambuhan klien gangguan jiwa berat rendah adalah 52.71 dengan standar deviasi 4.512 sedangkan untuk dukungan keluarga dengan kekambuhan tinggi, rata-rata kekambuhannya adalah 45.55 dengan standar deviasi 3.702 Secara statistik didapatkan nilai $p=0.000$ ada perbedaan yang signifikan antara dukungan keluarga dengan kekambuhan yang tinggi dan kekambuhan yang rendah, hal ini bisa ketahui dari jawaban keluarga yang menyatakan bahwa $18,8 \%$ keluarga menyatakan membantu anggota keluarga mencari informasi obat, $25.0 \%$ keluarga menyatakan membantu menyediakan minum dan buah-buahan dan $41.0 \%$ keluarga menyatakan menjelaskan efek samping obat dan cara minum obat. Hasil penelitian lain menyatakan bahwa klien jarang mendapatkan dukungan dari keluarga, sehingga klien tetap mengalami kekambuhan (Schennach, 2012).

Hasil ini sesuai dengan penelitian Priyanti (2012) dalam penelitiannya yang merekrut 51 pasien gangguan jiwa, melaporkan penyebab utama kekambuhan pada pasien jiwa yang dirawat di RSJD Atma Husada Mahakam Samarinda adalah $60.8 \%$ dukungan keluarga yang buruk. Hasil dari sebuah survei internasional sebanyak 838 responden yang dilakukan untuk menjelaskan pengalaman dan wawasan keluarga dengan salah satu anggota keluarga menderita gangguan jiwa di Australia, Kanada, Jerman, Perancis, Italia, Spanyol, Inggris dan Amerika Serikat, 85.34\% keluarga mengatakan anggota keluarga mereka mengalami kekambuhan karena keluarga tidak memberi dukungan yang disebabkan oleh keluarga yang sibuk terhadap pekerjaannya (69\%) (Sariah, 2012).

Hubungan Kepatuhan Minum Obat Dengan Kekambuhan Klien Gangguan Jiwa Berat di Unit Pelayanan Jiwa A RSJ. Prof. Dr. HB, Saanin Padang

Berdasarkan hasil penelitian didapatkan perbedaan yang signifikan antara rata-rata kepatuhan minum obat dengan kekambuhan klien gangguan jiwa berat yang tinggi dan kekambuhan yang rendah, rata-rata kepatuhan minum obat dengan kekambuhan klien gangguan jiwa berat yang rendah adalah 9.23 dengan standar deviasi 686, sedangkan rata-rata kepatuhan minum obat dengan kekambuhan yang tinggi adalah 7.84 dengan standar deviasi .1.034. Hasil uji statistik di dapatkan nilai $p=0.000$ ada perbedaan yang signifikan antara kepatuhan minum obat dengan kekambuhan klien gangguan jiwa berat yang tinggi dan kekambuah jiwa berat yang rendah.

Hasil ini juga sesuai dengan penelitian Schennach,at, al (2012) dalam penelitiannya yang merekrut 200 pasien klien gangguan jiwa, melaporkan $76 \%$ pasien yang mengalami kekambuhan dalam setahun disebabkan karena pasien tidak patuh terhadap pengobatan. Hasil penelitian ini sejalan dengan penelitian yang dilakukan oleh (Yudistira, dkk.2020) di dapatkan hasil lebih dari separuh dari responden tidak patuh minum obat yang mempunyai kekambuhan tinggi (67.8\%). artinya klien gangguan jiwa yang tidak patuh minum obat mempunyai resiko 3.716 kali mempunyai kekambuhan tinggi dibandingkan dengan yang patuh minum obat. Tidak patuhnya klien minum obat dapat disebabkan karena adanya gangguan realitas dan ketidak mampuan mengambil keputusan.

\section{Implikasi Penelitian}

\section{Bagi Pelayanan Keperawatan}

Implikasi penelitian ini bagi pelayanan keperawatan antara lain menjadi dasar bagi perawat jiwa sebagai landasan atau data awal terkait dukungan keluarga dan kepatuhan minum obat sehingga menjadi dasar pengobatan klien tidak hanya terhadap penurunan gejala tetapi juga berorientasi terhadap kekambuhan klien gangguan jiwa berat.

Hasil dari penelitian ini menunjukkan bahwa klien gangguan jiwa berat rata-rata berumur 40 tahun, berjenis kelamin laki-laki, berpendidikan rendah, tidak bekerja, belum menikah, pernah di 
rawat inap, lebih dari separuh mengalami kekambuhan tinggi. Terdapat perbedaan bermakna antara dukungan keluarga dengan tingkat kekambuhan yang tinggi dan kekambuhan yang rendah pada klien gangguan jiwa berat. Terdapat perbedaan bermakna antara kepatuhan minum obat dengan tingkat kekambuhan yang tinggi dan kekambuhan yang rendah pada klien gangguan jiwa berat

Faktor-faktor yang telah teridentifikasi mempunyai perbedaan yang bermakna terhadap kekambuhan klien gangguan jiwa berat diharapkan bisa menjadi referensi untuk mengembangkan ilmu keperawatan khususnya keperawatan jiwa dalam rangka meningkatkan intervensi keperawatan terkait terapi dalam meningkatkan penurunan angka kekambuhan klien gangguan jiwa berat dan intervensi kepada keluarga peningkatan dukungan keluarga.

\section{Kesimpulan}

Diketahuinya karakteristik umur klien gangguan jiwa berat 40.33, umur termuda 19 tahun dan umur tertua 65 tahun, jenis kelamin lebih dari separuh berjenis kelamin laki-laki $55.4 \%$, lebih dari separuh berpendidikian rendah $57.1 \%$, lebih dari separuh klien tidak bekerja 90.8\%, lebih dari separuh klien belum menikah 66.8 , lebih dari separuh klien pernah di rawat inap $57.1 \%$.

Klien gangguan jiwa berat di pelayanan jiwa A RSJ. Prof. HB, Saanin Padang didapatkan anlisis diketahui rata-rata kepatuhan minum obat responden secara keseluruhan adalah 8.67.

Klien gangguan jiwa berat di pelayanan jiwa A RSJ. Prof. HB, Saanin Padang didapatkan lebih dari separuh responden $(59.8 \%)$ responden mengalami kekambuhan tinggi.

Klien gangguan jiwa berat di pelayanan jiwa A RSJ. Prof. HB, Saanin Padang didapatkan rata-rata dukungan keluarga responden secara keseluruhan adalah 49.83. Skor dukungan keluarga terendah 38 dan dukungan tertinggi 63 .

Terdapat perbedaan bermakna antara dukungan keluarga dengan tingkat kekambuhan yang tinggi dan kekambuhan yang rendah pada klien gangguan jiwa berat
Terdapat perbedaan bermakna antara kepatuhan minum obat dengan tingkat kekambuhan yang tinggi dan kekambuhan yang rendah pada klien gangguan jiwa berat

\section{REFERENSI}

Collier, E. (2010) Confusion of recovery:one solution. International Journal of menthal Health Nursing,19,16-21. Dikases melalui http://web.ebscohost.com/ehost/pdf viewer?vid=4\&sid

Fleischhacker, W.,Oehl, MA. \& Hummer, M (2003) Factor Influencing Compliance in schizophrenia patients. Journla clin Psychiatry;64(suppl16;10-13)

Hughes, I., Hill, B\& Budd, R (1997) Compliance with antipsychotic medication: From theory to pratice. Journal of Mnetal Health, 6(5), 473489

Kazadi,N.J.B., Moosa, M.Y.H,. dan Jeenah, F.Y.(2008). Factors Associated with relapse in schizophrenia. SAJP 14(2), 52-62

Priyanti, 1. (2012). Faktor-faktor penyebab kekambuhan pada pasien skizofrenia di Unit Rawat Inap ATMA HUSADA MAHAKAM Samarinda Tahun 2012

Profil Dinas Kesehatan Kota Padang 2009.

RS. Jiwa. Prof. Dr. HB. Saanin Padang. Laporan kegiatan\&Program Kerja instalasi Rekam Medik: Rekam Medik

Sastroasmoro, S \& Ismael, S. (2011). Dasar-dasar metodologi penelitian klinis. Jakarta : CV. Sagung Seto

Schennach, dkk. (2012). Predictors of Relapse in the Year After Hospital Discharge Among Patients With Schizophrenia. Diakses pada tanggal 20 Maret2020darihttp://search.proquest .com/docview/1368609767/1433058 B7334C0FBB $\mathrm{A} / 1$ ? accountid $=50268$

Sariah, A . (2012). Factors influencing 
relapse among patients with schizophrenia in Muhimbili Nationa Hopspita: the perspectives of patiens and their caregivers. Di akses pada tanggal 24 Maret 2020 dari http://ir.muhas.ac.tz:8080/jspui/bitstrea $\mathrm{m} / 123456789 / 642 / 1 /$ Dissertation $\% 202$ $\% 20$ Adellah $\% 20$ Sariah $\% 20$ final $\% 20$ re port.pdf 